\title{
Hepatic metabolomics and transcriptomics to study susceptibility to ketosis in response to prepartal nutritional management
}

Khuram Shahzad ${ }^{1,2}$, Vincenzo Lopreiato ${ }^{3}$, Yusheng Liang ${ }^{2}$, Erminio Trevisi ${ }^{3}$, Johan S. Osorio ${ }^{4}$, Chuang Xu ${ }^{5}$ and Juan J. Loor ${ }^{2^{*}}$ (i)

\begin{abstract}
Background: Ketosis in dairy cows is associated with body fat mobilization during the peripartal period. Sub-clinical and clinical ketosis arise more frequently in cows that are overfed energy during the entire dry (last 50 to 45 days prior to parturition) or close-up period (last $\sim 28$ days prepartum).

Methods: A retrospective analysis was performed on 12 cows from a larger cohort that were fed a higher-energy diet [1.54 Mcal/kg of dry matter (DM); 35.9\% of DM corn silage and 13\% of DM ground corn] during the close-up dry period, of which 6 did not develop clinical ketosis (OVE, $0.83 \mathrm{mmol} / \mathrm{L}$ plasma hydroxybutyrate; BHB) and 6 were diagnosed with clinical ketosis (KET, $1.4 \mathrm{mmol} / \mathrm{L} \mathrm{BHB}$ ) during the first week postpartum. A whole-transcriptome bovine microarray (Agilent Technologies) and metabolomics (GC-MS, LC-MS; Metabolon ${ }^{\oplus}$ Inc.) were used to perform transcript and metabolite profiling of liver tissue harvested at -10 days relative to parturition which allowed to establish potential associations between prepartal transcriptome/metabolome profiles and susceptibility to clinical ketosis postpartum.

Results: Cows in KET had greater $(P=0.01)$ overall body weight between -2 and 1 week around parturition, but similar body condition score than OVE. Although dry matter intake (DMI) did not differ prepartum, KET cows had lower $(P<0.01) \mathrm{DMl}$ and similar milk yield as OVE cows during the first week postpartum. Transcriptome analysis revealed a total of 3065 differentially expressed genes (DEG; $P \leq 0.05)$ in KET. Metabolomics identified 15 out of 313 total biochemical compounds significantly affected $(P \leq 0.10)$ in KET. Among those, greater concentrations $(P \leq 0.06$, +2.3 -fold) of glycochenodeoxycholate in KET cows also have been detected in humans developing non-alcoholic fatty liver disease. Bioinformatics analysis using the Kyoto Encyclopedia of Genes and Genomes (KEGG) pathway database and the DEG revealed that, among the top 20 most-impacted metabolic pathway categories in KET, 65\% were overall downregulated. Those included 'Metabolism of cofactors and vitamins', 'Biosynthesis of other secondary metabolites', 'Lipid', 'Carbohydrate', and 'Glycan biosynthesis and metabolism'. The lower relative concentration of glucose-6-phosphate and marked downregulation of fructose-1,6-bisphosphatase 2 and pyruvate dehydrogenase kinase 4 support a strong impairment in gluconeogenesis in prepartal liver of cows developing KET postpartum. Among the top 20 most-impacted non-metabolic pathways, 85\% were downregulated. Pathways such as 'mTOR signalling' and 'Insulin signalling' were among those. 'Ribosome', 'Nucleotide excision repair', and 'Adherens junctions' were the only upregulated pathways in cows with KET.

(Continued on next page)
\end{abstract}

\footnotetext{
*Correspondence: jloor@illinois.edu

${ }^{2}$ Department of Animal Sciences and Division of Nutritional Sciences,

University of Illinois, Urbana, IL 61801, USA

Full list of author information is available at the end of the article
}

(c) The Author(s). 2019 Open Access This article is distributed under the terms of the Creative Commons Attribution 4.0 International License (http://creativecommons.org/licenses/by/4.0/), which permits unrestricted use, distribution, and reproduction in any medium, provided you give appropriate credit to the original author(s) and the source, provide a link to the Creative Commons license, and indicate if changes were made. The Creative Commons Public Domain Dedication waiver (http://creativecommons.org/publicdomain/zero/1.0/) applies to the data made available in this article, unless otherwise stated. 
(Continued from previous page)

Conclusions: The combined data analyses revealed more extensive alterations of the prepartal liver transcriptome than metabolome in cows overfed energy and developing ketosis postpartum. The causative link between these tissue-level adaptations and onset of clinical ketosis needs to be studied further.

Keywords: Bioinformatics, Ketosis, Metabolomics, Transition cow

\section{Background}

Dairy cows are highly susceptible to developing metabolic disorders such as ketosis during early lactation [1]. Ketosis can affect the profitability of dairy farms in terms of decreased milk production and treatment costs [2]. This disease is associated with negative energy balance (NEB), hepatic lipid accumulation, and increased concentration of blood hydroxybutyrate while blood glucose concentration is decreased [3]. Partial anorexia, lethargic behavior, and body fat mobilization also characterized the ketotic state [4]. The prepartal plane of energy nutrition is highly-correlated with body fat mobilization around parturition, and a greater susceptibility of cows for developing sub-clinical and clinical ketosis [5].

Although a number of studies have used 'omics' technology to study alterations in the transcriptome, proteome, and metabolome [6], the majority have addressed changes using liver tissue or plasma/serum in animals diagnosed with the disease $[7,8]$. To our knowledge, there are no studies using those tools that have address simultaneously a link between liver tissue omics data and the onset of clinical disease. Thus, the specific objective of the study was to use metabolomics and transcriptomics in liver tissue collected prepartum to explore not only profiles that are associated with postpartum onset of clinical ketosis, but the potential mechanisms at the liver-level that may render cows more susceptible. We used liver tissue harvested prior to parturition from a subset of cows in a previous study from our group [9] that were fed a higher-energy diet during the last 3 weeks prepartum to assess differences in prepartum liver tissue and their association with clinical ketosis outcome in the first week postpartum. Bioinformatics analyses were applied to attempt to integrate transcriptome and metabolome data.

\section{Methods}

All the procedures for this study were approved by The Institutional Animal Care and Use Committee (IACUC) of the University of Illinois at Urbana-Champaign under the protocol No. 09214.

\section{Experimental design and dietary treatments}

The experiment was conducted as a randomized complete block design as explained elsewhere [9] using multiparous Holstein dairy cows. For the present analysis, we used a subset of 12 cows from the full cohort that were overfed and did not develop clinical ketosis (OVE, $n=6)$ or developed clinical ketosis postpartum (KET, $n=6)$. Ketosis was determined during the first 7 days postpartum by testing urine with Ketostix reagent strips (Bayer Corp., Pittsburgh, $\mathrm{PA})$, which measures acetoacetic acid, a ketone. Urine acetoacetic acid $>80 \mathrm{mg} / \mathrm{dL}$ was used for the initial diagnosis of KET. All KET cows in the present study had "large ketones" in the urine, went off-feed, and had to be treated by the attending veterinarian with i.v. glucose before returning to the herd. All cows received the same faroff diet $[1.24 \mathrm{Mcal} / \mathrm{kg}$ of dry matter (DM); $14.3 \%$ crude protein $(\mathrm{CP})]$ from -50 to -20 days before expected calving, a higher-energy close-up diet $(1.54 \mathrm{Mcal} / \mathrm{kg}$ of DM; $15.0 \% \mathrm{CP}$ ) from -21 days to calving, and a common fresh cow lactation diet $(1.75 \mathrm{Mcal} / \mathrm{kg}$ of DM, $17.5 \% \mathrm{CP})$ from calving through 30 days in milk. To increase energy density in the close-up diet, corn silage inclusion went from $33 \%$ to $35.9 \%$ of DM and ground corn from $4 \%$ to $13 \%$ of DM, while wheat straw was reduced from $36 \%$ to $15.4 \%$ of DM. Composition of the total mixed rations, details of blood sampling, and responses in terms of health outcomes and production in the larger cohort of cows have been reported previously [9]. Body weight (BW), body condition score (BCS), dry matter intake (DMI), milk yield, and plasma biomarkers for cows used in the present study are reported herein.

\section{Liver biopsies and RNA extraction}

Liver tissue samples were collected via puncture biopsy [10] from cows under local anesthesia at approximately $07: 30 \mathrm{~h}$ once prepartum on day -10 ( \pm 3 days) for this study. Details on tissue storage were reported previously [9]. Briefly, liver tissue samples were immediately placed in screw-capped microcentrifuge tubes, snapfrozen in liquid nitrogen, and preserved at $-80^{\circ} \mathrm{C}$ until further analysis. Specific details of RNA isolation from liver, primer design, evaluation, and quantitative real time PCR are reported elsewhere [11]. RNA concentration was measured using a Nano-Drop ND-1000 spectrophotometer (Nano-Drop Technologies, Wilmington, DE, USA). The purity of RNA (A260/A280) for all samples was above 2.0. The quality of RNA was evaluated using the Agilent Bioanalyzer system (Agilent 2100 Bioanalyzer, Agilent Technologies, Santa Clara, CA, USA). The average RNA integrity number values for all samples was 7.9. 


\section{Transcriptome and metabolome experiment}

The microarray experiment was performed using the $44 \mathrm{~K}$ bovine (v2) gene expression Agilent platform. Protocols were exactly as described in our previous publications [12, 13]. Metabolomics analysis was performed using GC-MS/LC-MS by Metabolon Inc. (Morrisville, NC, USA). Frozen tissue was shipped in dry ice and processed according to company protocols (http://www. metabolon.com).

\section{Plasma profiling of physiologic biomarkers}

Plasma biomarker concentrations were measured at $-12,-3$ and +3 days relative to parturition using exactly the same commercial kits and protocols as reported in our previous publications [14-16]. Routine evaluation of ketosis was performed by the attending veterinarian during the first 7 days postpartum using urine samples and a reagent strip [17]. Cows that were identified as clinically ketotic (ketones $>80 \mathrm{mg} / \mathrm{dL}$ ) were immediately treated by the attending veterinarian with intravenous dextrose. Per Animal Care and Use Committee guidelines, once cows were diagnosed they were removed from the experiment and further blood or tissue samples could not be harvested.

\section{Statistical analysis}

The statistical analysis of transcriptome data was performed using 12 microarrays. The data were log-transformed and then corrected for dye and array effects using loess normalization. After data normalization, the mixed procedure of SAS (SAS Institute Inc., Cary, NC) was used to determine differential gene expression. The statistical model included health status as the fixed effect. Differentially expressed genes (DEG) were detected at a False discovery rate $P \leq 0.05$ and a fold change (FC) of KET versus OVE of $\geq 1.5$.

The statistical analysis of metabolomics data was performed across a total of 313 biochemical compounds identified. The raw values resulting from GC-MS/LCMS analysis were normalized in terms of raw area counts. The raw values from each biochemical compound were rescaled to set the median value equal to 1 . The missing values were imputed with the minimal value. Following log-transformation and imputation of missing values, if any, with the minimal observed value for each compound, the MIXED procedure of SAS was used to identify compounds that differed significantly between OVE and KET. Data for DMI and milk yield, BW and BCS, plasma systemic biomarkers of energy balance, liver function, and immune status were subjected to ANOVA and analyzed using the repeated measures statement in the MIXED procedure of SAS. The model included days or weeks relative to parturition, health status (KET vs. OVE), and their interaction as fixed effects, and cow within health status group as random effect.

\section{Network analysis and data integration}

The network analysis of transcriptomics data was conducted using Ingenuity Pathway Analysis (IPA; Ingenuity Systems). The list of DEG was uploaded to run the core analysis, focusing on upstream transcription regulators and their downstream target genes. For the metabolomics network reconstruction, the list of significant compounds were annotated against the PubChem biochemical database and used for the IPA analysis.

\section{KEGG pathway analysis}

The dynamic impact approach (DIA) [18] was used for pathway analysis using the Kyoto Encyclopedia of Genes and Genomes (KEGG) database. As with the IPA analysis, the full list of DEG was used. The DIA allows for an assessment of the 'impact' (biological relevance) and 'flux' (direction of the impact, downregulation or upregulation) within KEGG pathways as a function of the DEG list. The entire DEG also were used in the KegArray tool (http://www.kegg.jp/) to obtain an overall picture of the top 20 metabolic and non-metabolic KEGG pathways that resulted from the DEG. When feasible, the biochemical compounds identified from metabolomics analysis were further annotated with their corresponding pathways.

\section{Results and discussion}

There is a substantial body of information encompassing classical biochemistry and novel omics tools to characterize ketosis [6]. Unlike characterization of the physiologic changes during the disease, few data exist on the profiles of genes, proteins, and/or metabolites in liver tissue that may predispose the cow to developing clinical ketosis. In the present study, transcriptomic and metabolomics were combined to uncover changes occurring at the gene, metabolite, and pathway level. This degree of integration represents an initial attempt to better understand the potential culprits of ketosis development at the liver level before parturition. A clear outcome of the present study was that there were fewer changes at the metabolome than transcriptome level.

A total of 3065 differentially expressed genes in the KET vs. OVE (Additional file 1) were detected at a $P$ value cut-off of $\leq 0.05$ and an FC threshold of $\geq|1.5|$. Among these, 2091 were upregulated and 974 were downregulated. By reducing the $P$ value cut-off to $\leq 0.01$ and doubling the FC threshold to $\geq|3|$, a total of 121 DEG were obtained, of which 22 were upregulated (fold change $\geq 3$ ) (Table 1) and 39 were downregulated (fold change $\leq-4)$ (Table 2). Overall, a mixed response in 
Table 1 Differentially expressed genes with a $P$-value $<0.01$ and fold change $\geq 3$ in liver tissue harvested 10 days prior to parturition from Holstein cows with (KET) or without (OVE) clinical ketosis during the first week postpartum. Both groups of cows were fed a diet containing $1.54 \mathrm{Mcal} / \mathrm{kg}$ of dry matter and $15.0 \%$ crude protein from - 21 days prepartum to calving, and a common lactation diet containing $1.75 \mathrm{Mcal} / \mathrm{kg}$ of dry matter and $17.5 \%$ crude protein

\begin{tabular}{|c|c|c|}
\hline Symbol & Description & KET vs. OVE \\
\hline CCL2 & Chemokine (C-C motif) ligand 2 (CCL2) & 5.12 \\
\hline CLCA2 & Chloride channel accessory 2 & 5.09 \\
\hline CACNAID & Calcium channel, voltage-dependent & 4.51 \\
\hline ADARB2 & Adenosine deaminase, RNA-specific & 4.51 \\
\hline KRT9 & Keratin 9 & 4.45 \\
\hline KIFC2 & Kinesin family member C2 & 4.34 \\
\hline MARK1 & MAP/microtubule affinity-regulating kinase 1 & 4.22 \\
\hline POLE2 & Polymerase (DNA directed), epsilon 2 (p59 subunit) & 4.19 \\
\hline SLC22A2 & Solute carrier family 22 (organic cation transporter), member 2 & 4.06 \\
\hline GPR63 & G protein-coupled receptor 63 & 3.98 \\
\hline ANO3 & Anoctamin 3 & 3.88 \\
\hline$X K$ & X-linked Kx blood group (McLeod syndrome) & 3.83 \\
\hline DUSP4 & Dual specificity phosphatase 4 & 3.73 \\
\hline SPATA7 & Spermatogenesis associated 7 & 3.64 \\
\hline $\mathrm{ZC} 3 \mathrm{H} 4$ & Zinc finger $\mathrm{CCCH}$-type containing 4 & 3.59 \\
\hline SYCE3 & Synaptonemal complex central element protein 3 & 3.57 \\
\hline MYRIP & Myosin VIIA and Rab interacting protein & 3.40 \\
\hline LOC787081 & Predicted: UPF0632 protein A & 3.36 \\
\hline CNR1 & Cannabinoid receptor 1 (brain) & 3.21 \\
\hline SPATA17 & Predicted: spermatogenesis associated 17 & 3.20 \\
\hline PCBP3 & Poly(rC) binding protein 3 (PCBP3) & 3.09 \\
\hline ADAM32 & ADAM metallopeptidase domain 32 (ADAM32) & 3.08 \\
\hline
\end{tabular}

terms of up and downregulated DEG was observed within metabolism and immune system pathways.

For metabolomics analysis, we used a $P \leq 0.10$ threshold to determine significantly affected biochemical compounds (Table 4). Using this selection criterion resulted in a total of 18 affected biochemical compounds, of which 4 were upregulated and the remaining downregulated. A full list of 313 biochemical compounds identified can be found in the Additional file 2. The statistical analysis of DMI and milk yield and plasma systemic biomarkers of energy balance, liver function, and inflammation are reported in Fig. 1, Fig. 2, and Additional file 3. Despite KET cows having lower overall $(P<0.01)$ DMI compared with OVE due to the response after parturition, milk production did not differ statistically. The lower DMI postpartum in KET cows was associated with greater $(P<0.05)$ BHB compared with OVE cows, in fact, confirming that KET cows underwent a more severe degree of NEB that eventually led to a clinical condition.

The metabolomics analysis identified biomarkers related to various aspects of lipid, amino acid, and carbohydrate metabolism (Table 4). Among these, cows in KET had greater relative concentrations of lipid-related metabolites such as glycochenodeoxycholate and butyrylglycine along with 1-methylimidazoleacetate from histidine metabolism, whereas various amino acid-related metabolites such as dipeptides, kynurenine, and lipid-related compounds such as 1-palmitoylglycerophosphoglycerol, Derythro-C16-ceramide (also known as N-palmitoyl-D-erythro-sphingosine), 3-dehydrocarnitine, tetradecanedioate, and 1-oleoylglycerophosphoethanolamine were lower. The phosphatidylcholine intermediate metabolite cytidine $5^{\prime}$ diphosphocholine also was greater in KET cows.

In general, in terms of metabolite categories, the present metabolomics results are somewhat similar to those reported recently in serum of dairy cows that developed clinical mastitis postpartum [19]. It is also noteworthy that the present data are closely related to blood metabolomics comparisons performed to study non-alcoholic fatty liver disease (NAFLD) [20]. For instance, just as in the present study, the concentrations of glycochenodeoxycholate and various other bile acids were markedly greater in humans 
Table 2 Differentially expressed genes with a $P$-value $<0.01$ and fold change $\leq-4$ in liver tissue harvested 10 days prior to parturition from Holstein cows with (KET) or without (OVE) clinical ketosis during the first week postpartum. Both groups of cows were fed a diet containing $1.54 \mathrm{Mcal} / \mathrm{kg}$ of dry matter and $15.0 \%$ crude protein from -21 days prepartum to calving, and a common lactation diet containing $1.75 \mathrm{Mcal} / \mathrm{kg}$ of dry matter and $17.5 \%$ crude protein

\begin{tabular}{|c|c|c|}
\hline Symbol & Description & KET vs. OVE \\
\hline DOCK3 & Dedicator of cytokinesis 3 & -8.12 \\
\hline FAM131A & Family with sequence similarity 131 , member $\mathrm{A}$ & -6.91 \\
\hline LOC528412 & Multidrug resistance-associated protein 4 & -6.80 \\
\hline COBRA1 & Cofactor of BRCA1 & -6.24 \\
\hline CPXM2 & Carboxypeptidase X (M14 family), member 2 & -6.13 \\
\hline UNC13D & Unc-13 homolog D (C. elegans) & -5.18 \\
\hline LOC780781 & Keratin associated protein & -5.11 \\
\hline BTBD10 & BTB (POZ) domain containing 10 & -5.09 \\
\hline$B A D$ & BCL2-associated agonist of cell death & -5.08 \\
\hline NEU4 & Sialidase 4 & -5.08 \\
\hline SS18 & Synovial sarcoma translocation, chromosome 18 & -4.82 \\
\hline TAPBPL & TAP binding protein-like & -4.80 \\
\hline KIAA0922 & KIAA0922 ortholog & -4.77 \\
\hline$A P O B R$ & Apolipoprotein B receptor & -4.68 \\
\hline PROK2 & Prokineticin 2 & -4.64 \\
\hline WDR6 & WD repeat domain 6 & -4.60 \\
\hline EVC2 & Ellis van creveld syndrome 2 & -4.58 \\
\hline SYN3 & Synapsin III & -4.50 \\
\hline GLCCI1 & Glucocorticoid induced transcript 1 & -4.50 \\
\hline DLGAP5 & Discs, large (Drosophila) homolog-associated protein 5 & -4.47 \\
\hline CIB2 & Calcium and integrin binding family member 2 & -4.47 \\
\hline TBC1D19 & TBC1 domain family, member 19 & -4.41 \\
\hline ARNT & Aryl hydrocarbon receptor nuclear translocator & -4.40 \\
\hline ACPT & Acid phosphatase, testicular & -4.40 \\
\hline MAPK3 & Mitogen-activated protein kinase 3 & -4.39 \\
\hline TUBG1 & Tubulin, gamma 1 & -4.39 \\
\hline NCOA2 & Nuclear receptor coactivator 2 & -4.29 \\
\hline REN & Renin & -4.25 \\
\hline DST & Predicted: Dystonin, transcript variant 1 & -4.23 \\
\hline PTK2 & PTK2 protein tyrosine kinase 2 & -4.21 \\
\hline HCN1 & Hyperpolarization activated cyclic nucleotide-gated potassium channel 1 & -4.20 \\
\hline DEFB1 & Defensin, beta 1 & -4.16 \\
\hline TTF2 & Transcription termination factor, RNA polymerase II & -4.13 \\
\hline NPB & Neuropeptide B & -4.13 \\
\hline RAB27A & RAB27A, member RAS oncogene family & -4.09 \\
\hline ZYG11A & Zyg-11 homolog A (C. elegans) & -4.08 \\
\hline MAP3К & Mitogen-activated protein kinase kinase kinase 4 & -4.06 \\
\hline TPGS1 & Predicted: Chromosome 7 open reading frame, human C19orf20 & -4.04 \\
\hline CIQTNF3 & $\mathrm{Clq}$ and tumor necrosis factor related protein 3 & -4.00 \\
\hline
\end{tabular}



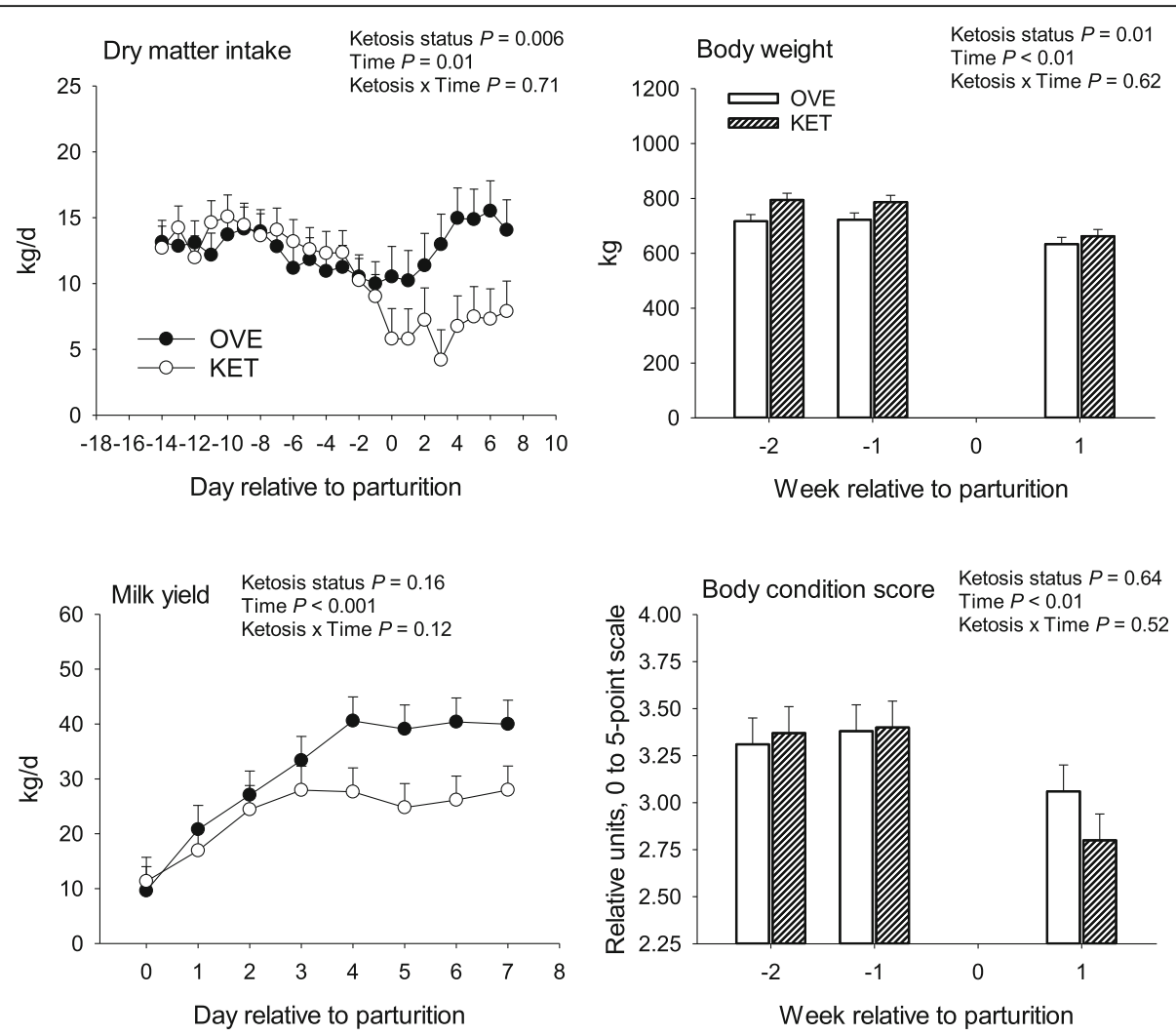

Fig. 1 Dry matter intake (DMI), milk yield, body weight, and body condition score in cows overfed energy prepartum that developed ketosis within 7 days postpartum (KET) or remained healthy (OVE). Both groups of cows were fed a diet containing $1.54 \mathrm{Mcal} / \mathrm{kg}$ of dry matter and $15.0 \%$ crude protein from - 21 days prepartum to calving, and a common lactation diet containing $1.75 \mathrm{Mcal} / \mathrm{kg}$ of dry matter and $17.5 \%$ crude protein

with NAFLD [20, 21]. Unlike humans with NAFLD, however, cows with KET did not have greater concentrations of carnitine-related metabolites or kynurenine.

\section{Networks of transcription regulators, biochemical compounds and their integration}

The network analysis for both DEG and biochemical compounds was conducted using IPA software. For DEG, we used the upstream analysis tool in IPA to identify transcription regulators among the DEG (Suppl. File 1). There were in total 9 upregulated and 3 downregulated transcription regulators among the DEG. The network of the 4 upregulated transcription regulators for which IPA identified connections within the list of DEG is shown in Fig. 3a. The upregulated transcription regulators were HMGB1 (high mobility group box 1), HOXA13 (homeobox protein Hox-A13), SREBF2 (sterol regulatory element binding transcription factor 2), MECOM (MDS1 and EVI1 complex locus protein EVI1), NKX2-1 (NK2 homeobox 1), SATB1 (special AT-rich sequence binding protein 1), HIF1A (hypoxia-inducible factor 1-alpha), and NFE2L2 (nuclear factor erythroid 2-like 2) (Suppl. File 1).
Among upregulated transcription regulators, $H M G B 1$, STAB1 (stabilin 1), and NFE2L2 are involved in immune response, oxidative stress, and inflammation. Both HOXA13 and $M E C O M$ are involved in gene regulation, cell development, differentiation, and proliferation. Hypoxia-inducible factor 1-alpha plays an important role in cellular response to systemic oxygen levels, and glucose metabolism and iron homeostasis. At least in non-ruminants, but also in cows with clinical ketosis [22], SREBF2 controls cholesterol homeostasis by regulating transcription of sterol-regulated genes. NKX2-1 also known as 'thyroid specific enhancer binding protein' is involved in the regulation of genes associated with the thyroid, lung, and diencephalon.

The downregulated transcription regulators were CSHL1 (chorionic somatomammotropin hormone-like 1), NCOA2 (nuclear receptor coactivator 2), HDAC5 (histone deacetylase 5), GLI3 (Zinc finger protein GLI3), SKIL (SKI-Like proto-oncogene), SPIB (Spi-B transcription factor), and SNAI1 (Snail family zinc finger 1). The network of the top 3 most-downregulated transcription regulators is shown in Fig. 3b. These genes are involved in functions (https:// www.ncbi.nlm.nih.gov/gene/) including cell growth control (CSHL1), transcriptional activity and cell signaling (GLI3, 

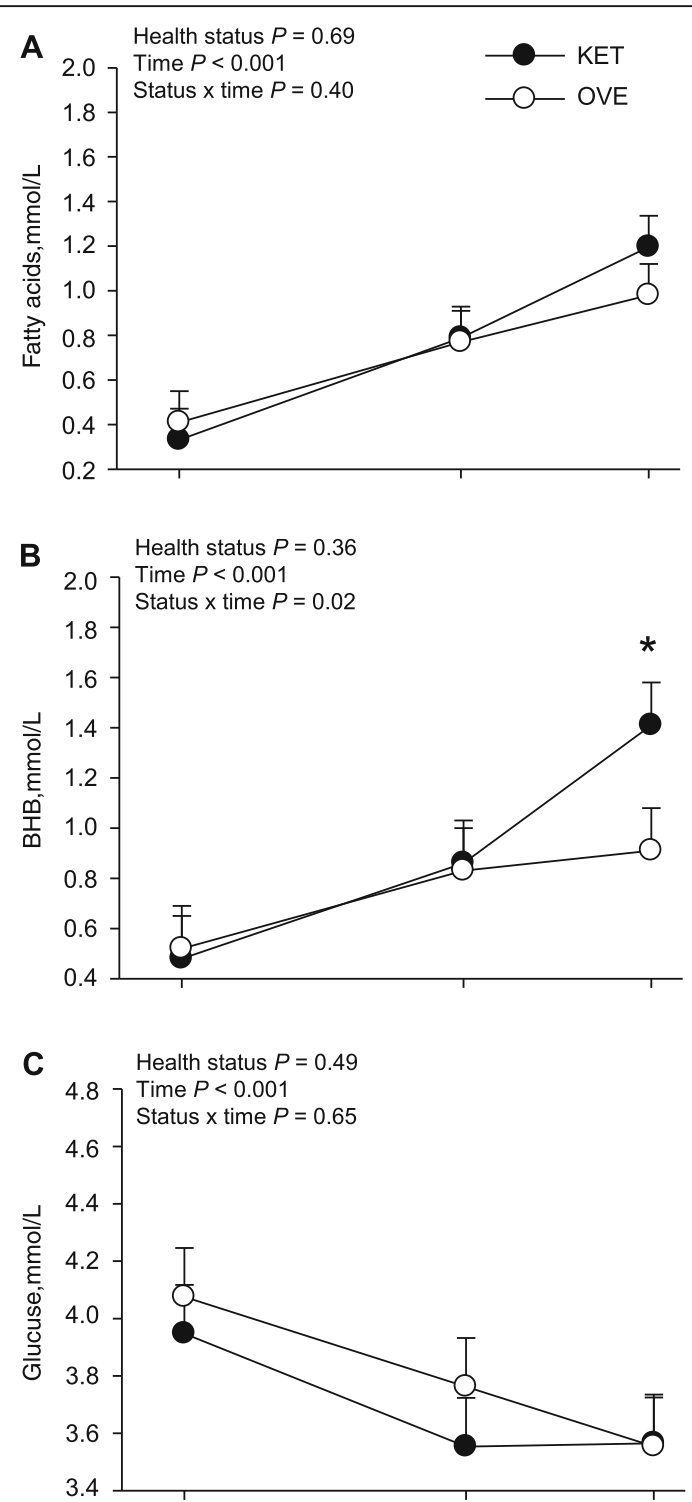

D Health status $P=0.49$

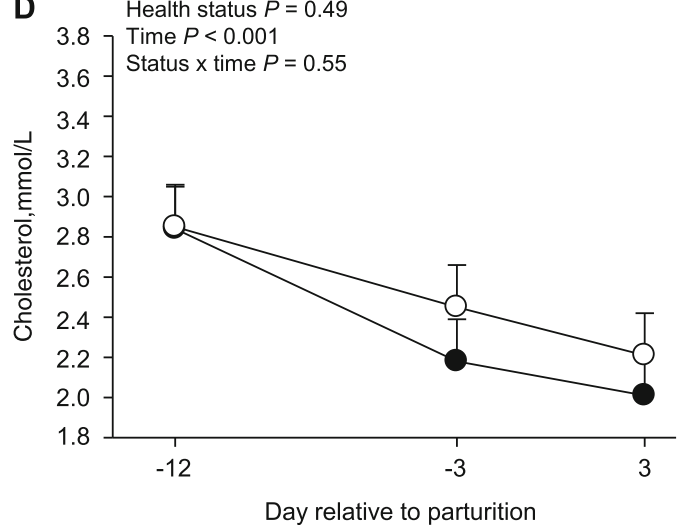

Fig. 2 Plasma concentrations of fatty acids (a), hydroxybutyrate $(\mathrm{BHB} ; \mathbf{b})$, glucose (c), and cholesterol (d) around parturition in cows overfed energy prepartum that developed ketosis within 7 days postpartum (KET) or remained healthy (OVE). * Means differ (status $\times$ time). Both groups of cows were fed a diet containing $1.54 \mathrm{Mcal} / \mathrm{kg}$ of dry matter and $15.0 \%$ crude protein from -21 days prepartum to calving, and a common lactation diet containing $1.75 \mathrm{Mcal} / \mathrm{kg}$ of dry matter and $17.5 \%$ crude protein

SNAI1), transcriptional regulation, cell cycle progression, growth and differentiation (HDAC5, SKIL, SPIB), and nuclear hormone receptors including steroid, thyroid, retinoid, and vitamin D receptors (NCOA2).

The network analysis between biochemical compounds and biological processes in the IPA knowledgebase is shown in Fig. 4. Among the 13 biochemical compounds significantly affected in KET cows, glucose-6-phosphate, glycochenodeoxycholate, and D-erythro-C16-ceramide could be mapped against known cellular functions in the IPA knowledgebase (Fig. 4).

Figure 5 depicts data integration with the IPA knowledgebase using transcription regulators and biochemical compounds identified as significantly affected in cows with KET. The transcription regulators are linked with other potential downstream genes (with white background) and biochemical compounds (with white background) via direct and indirect relationships (according to the IPA legend). Although metabolomics research including nuclear magnetic resonance (NMR), mass spectrometry coupled with either liquid chromatography (LC-MS) or gas chromatography (GC-MS) [23] have been used to different degrees in research with transition cows [24, 25], only few examples of dataset integration exist [26] and none (to our knowledge) focused on the liver.

\section{KEGG pathways}

Results from the DIA analysis using KEGG with the mostaffected biological subcategories are reported in Figs. 6 and 7. Among results from the DIA analysis, the discussion in the sections below concerns 'metabolic' (Fig. 6) and 'non-metabolic' (Fig. 7) pathways, with a focus on the top 20 most-impacted pathways in cows that developed ketosis. The term "impact" refers to the biological importance of a given pathway as a function of the change in expression of genes composing the pathway (proportion of DEG and their magnitude) [18]. Consequently, the direction of the impact, or flux, characterizes the average change in expression as up-regulation/activation, downregulation/inhibition, or no change.

\section{Metabolic pathways}

\section{Carbohydrate metabolism}

The downregulation of 'Pentose phosphate pathway', 'Inositol phosphate metabolism', and 'Glycolysis / Gluconeogenesis' 


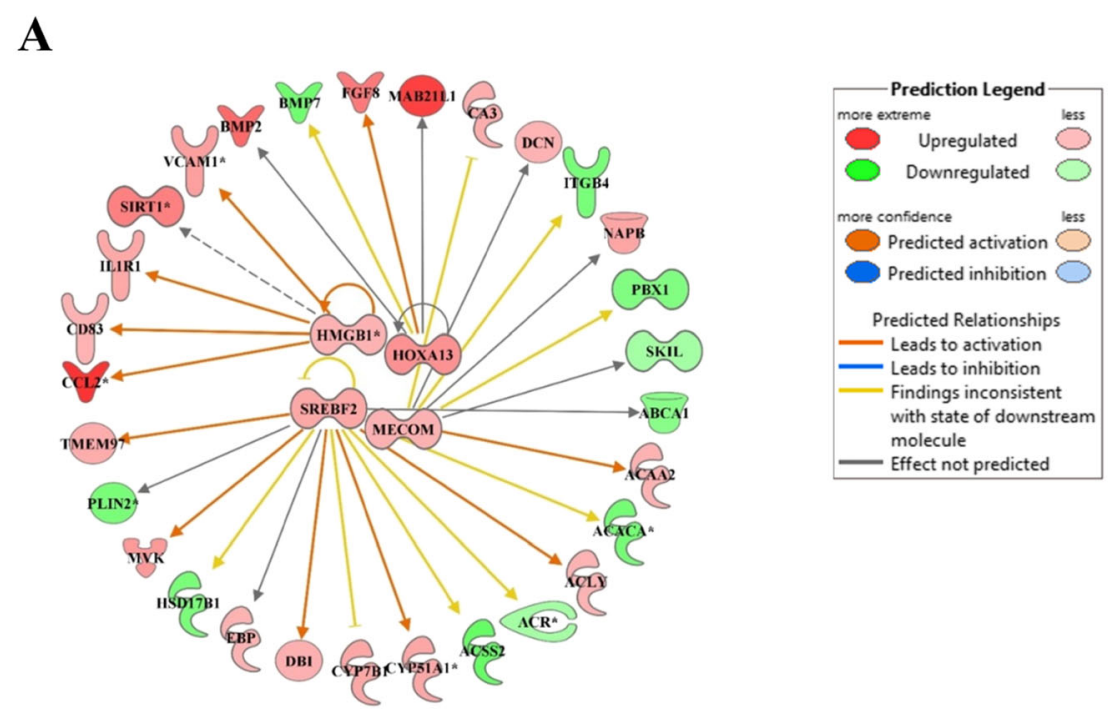

B

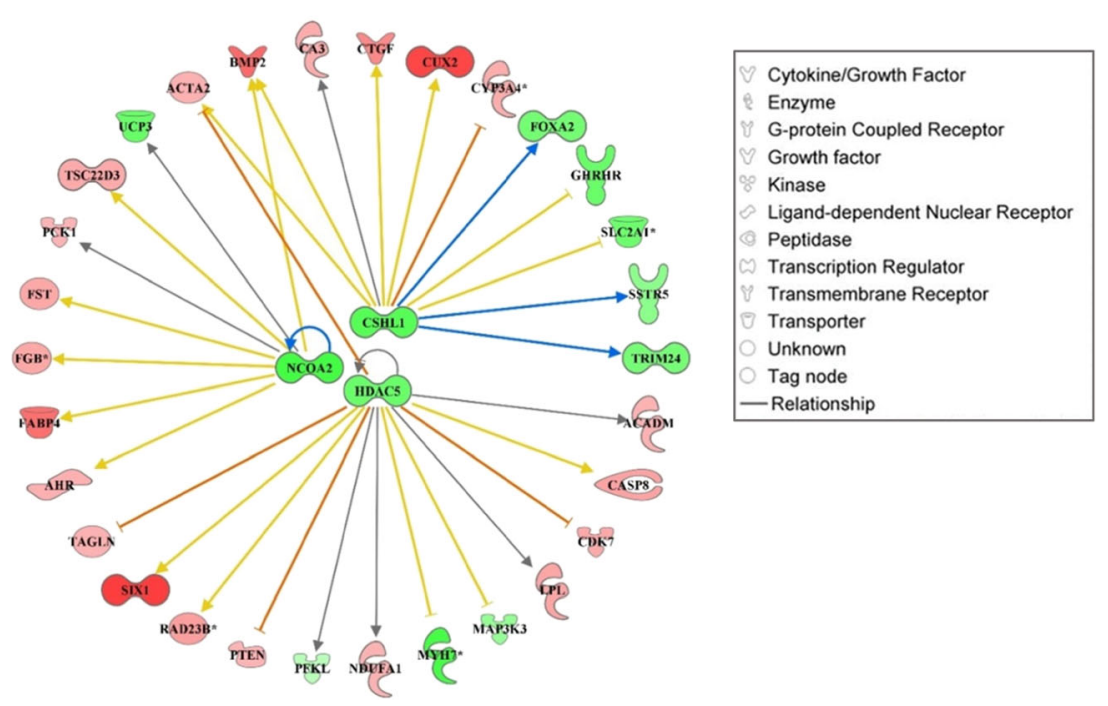

Fig. 3 Network analysis using Ingenuity Pathway Analysis (IPA) among 4 upregulated (a: HMGB1, HOXA13, SREBF2, MECOM) and 3 downregulated (b: NCOA2, CSHL1, HDAC5) transcription factors and differentially expressed genes due to onset of ketosis postpartum. Both groups of cows were fed a diet containing $1.54 \mathrm{Mcal} / \mathrm{kg}$ of dry matter and $15.0 \%$ crude protein from - 21 days prepartum to calving, and a common lactation diet containing $1.75 \mathrm{Mcal} / \mathrm{kg}$ of dry matter and $17.5 \%$ crude protein

with KET (Fig. 6, Additional file 1), and the marked negative effect on various individual genes associated with glycolysis and gluconeogenesis (Table 3) underscores the importance of normal hepatic carbohydrate metabolism to prevent ketosis. The most remarkable effect detected in KET cows was the marked downregulation of fructose-1,6bisphosphatase 2 (FBP2; Table 3) that, despite the modest upregulation of well-known gluconeogenic genes (e.g. PFKFB2, PCCA, and PCK1), would have compromised the ability of the liver to generate glucose during the last stages of pregnancy when cows voluntarily reduce DMI [1]. The lower concentration of glucose-6-phosphate (G6P), xylitol, and ribulose revealed by metabolomics (Table 4) support the inhibition not only of glycolysis/gluconeogenesis, but also pentose metabolism.

Xylitol is a normal metabolite of the glucuronatexylulose pathway in mammals, with small amounts being synthesized from glucose in certain tissues (e.g. adipose) [27]. In rodent and human liver, xylitol is metabolized mainly to xylulose 5-phosphate in the pentose phosphate pathway [28]. It is noteworthy that early studies in nonruminants not only demonstrated that xylitol is gluconeogenic, but also that it is a potent insulin secretagogue [29]. The fact that in the sole published study with dairy cows xylitol infusion increased plasma glucose and 

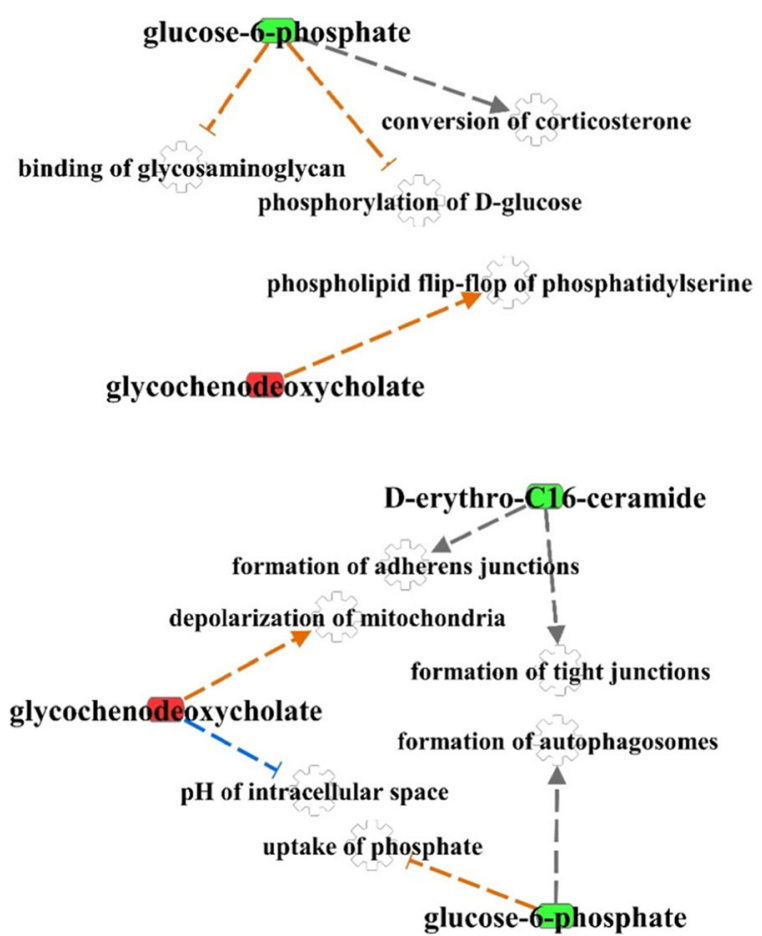

Fig. 4 Representation of biochemical compounds in the form of metabolic (A: carbohydrate and lipid metabolism) and non-metabolic (B: cellular functions) networks in cows overfed energy prepartum that developed ketosis within 7 days postpartum (KET) or remained healthy (OVE). Both groups of cows were fed a diet containing $1.54 \mathrm{Mcal} / \mathrm{kg}$ of dry matter and $15.0 \%$ crude protein from - 21 days prepartum to calving, and a common lactation diet containing $1.75 \mathrm{Mcal} / \mathrm{kg}$ of dry matter and $17.5 \%$ crude protein

decreased BHB without changing plasma fatty acids indicates this compound is biologically relevant in the context of glucose homeostasis [30].

\section{Lipid metabolism}

Among the lipid metabolic pathways within the top 20 most-impacted pathways (Fig. 6), 'Steroid biosynthesis' and 'Sphingolipid metabolism' were induced in the KET vs. OVE group. The 'Synthesis and degradation of ketone bodies' (Additional file 1) was the most induced pathway within lipid metabolism in the ketotic group. Together with the negative alterations in carbohydrate metabolism-related pathways, the results suggest that cows predisposed to developing postpartal ketosis as a result of energy overfeeding prepartum are primed partly through altering hepatic ketone body synthesis.

'Primary bile acid synthesis' and 'Primary bile acid metabolism' were induced in KET vs. OVE cows (Additional file 1 and Table 3, respectively), a response that agrees with the greater relative concentration of glycochenodeoxycholate (Fig. 4a). Liver is the main site of bile acid production, which in turn helps reduce excessive concentrations of free cholesterol in the liver [31]. The concentrations of bile acids in liver and peripheral blood can be influenced by various factors including synthesis, transport across membranes, secretion, enterohepatic recirculation, liver glycine- or taurine- conjugation, and fecal elimination. Although we did not detect differences in plasma cholesterol between KET and OVE cows (Fig. 2), upregulation of genes involved in cholesterol synthesis/metabolism such as CYP7B1 and SREBF2 (Additional file 1) [26] along with the marked downregulation of $A P O B R$ (Table 2) suggest important alterations not only in the ability of the liver to recycle cholesterol from lipoproteins, but also to use it for synthesis of bile acids.

In the first hepatic transcriptome study of clinical ketosis, we reported a marked downregulation of SREBF2 [22], which is clearly opposite to the present study, suggesting an effect in the regulation of sterol biosynthesis [32]. At least in non-ruminants, the SREBF2 transcription regulator encodes the crucial protein controlling target enzymes involved in de novo cellular cholesterol synthesis, with its activation promoting hepatocyte cholesterol accumulation [33, 34]. In humans with NAFLD, hepatic expression of SREBF2 and its target genes was upregulated, with the degree of SREBF2 activation paralleling the severity of hepatic cholesterol overload [35, 36]. Thus, we speculate that KET cows were prone to accumulate greater levels of cholesterol in the liver in the prepartum, potentially as a result of the downregulation of lipoprotein uptake through $A P O B R$ [37]. From a mechanistic standpoint, we speculate that the overload of cholesterol in liver prior to parturition 

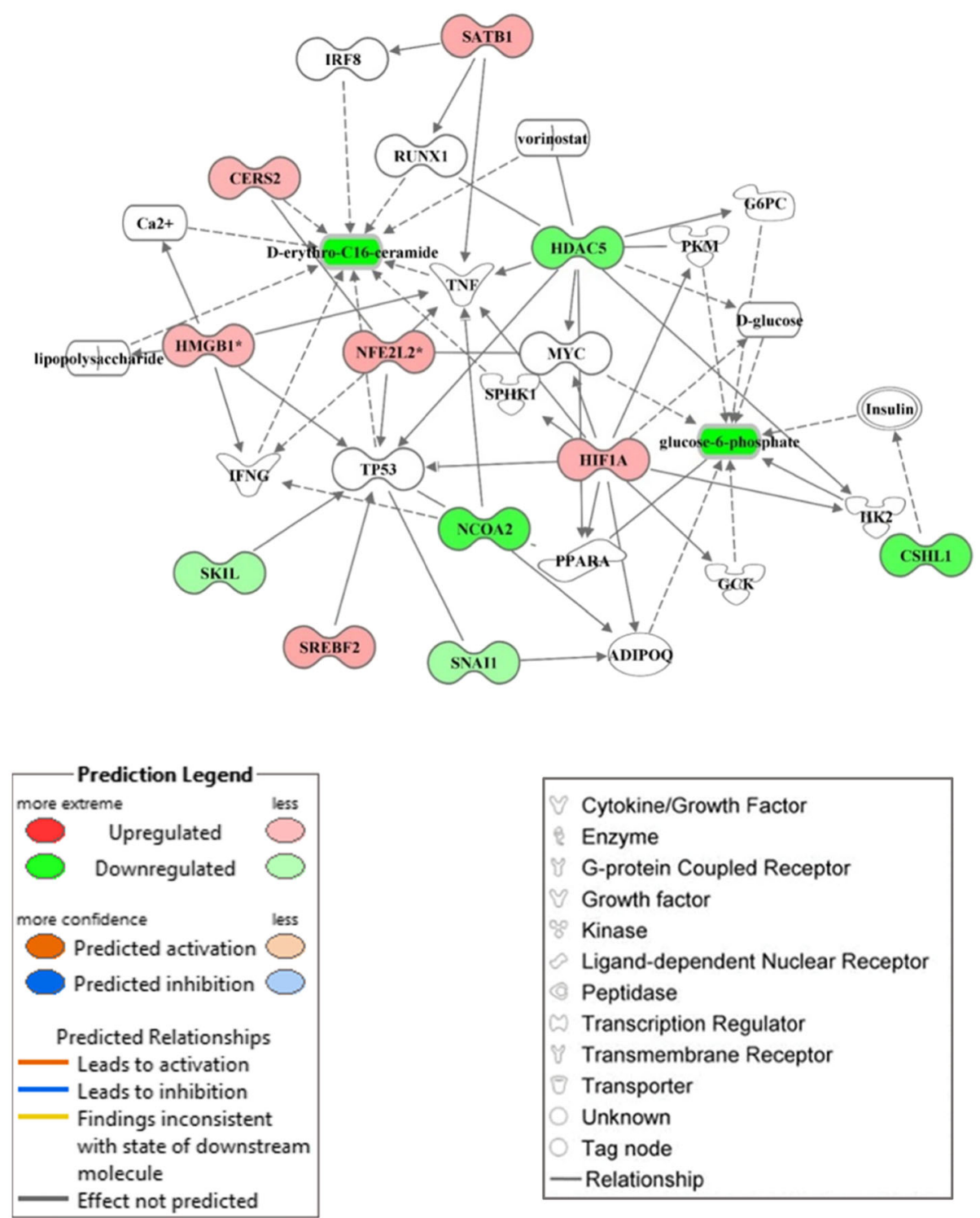

Cytokine/Growth Factor
Enzyme
G-protein Coupled Receptor
Growth factor
Kinase
Ligand-dependent Nuclear Receptor
Peptidase
Transcription Regulator
Transmembrane Receptor
Transporter
Unknown
Tag node

Fig. 5 Data integration from transcription regulators and biochemical compounds in cows overfed energy prepartum that developed ketosis within 7 days postpartum (KET) or remained healthy (OVE). Both groups of cows were fed a diet containing $1.54 \mathrm{Mcal} / \mathrm{kg}$ of dry matter and $15.0 \%$ crude protein from - 21 days prepartum to calving, and a common lactation diet containing $1.75 \mathrm{Mcal} / \mathrm{kg}$ of dry matter and $17.5 \%$ crude protein

might increase the risk of ketosis after parturition because the overall inflammatory status that characterizes this period results in impaired very low density lipoprotein (VLDL) secretion from the liver. A range of thresholds and methods can be used for ketosis diagnosis, for example, detection in milk, blood, and urine samples [38]. Thus, the lack of statistical differences in blood biomarkers related to inflammation and oxidative stress in the present study underscores that other factors such as parity, time at harvest of samples and BCS could influence diagnosis results [39, 40]. Although the various plasma biomarkers of inflammation and oxidant status did not differ (Additional file 3), overall, the present data underscore the potential involvement of lipoprotein and cholesterol metabolism in the liver as important causative factors for ketosis.

\section{Amino acid metabolism}

The greater relative concentration of butyrylglycine and 1-methylimidazoleacetate agrees with the induction of 'Glycine, serine, and threonine metabolism' and 'Histidine metabolism' in KET cows (Additional file 1). The 


\begin{tabular}{|l|l|l|}
\hline \multicolumn{1}{|c|}{ Sub-Category } & \multicolumn{1}{|c|}{ Metabolic Pathways } \\
\hline 1.8 Metabolism of Cofactors and Vitamins & Riboflavin metabolism \\
1.10 Biosynthesis of Other Secondary Metabolites & Caffeine metabolism \\
1.7 Glycan Biosynthesis and Metabolism & Other glycan degradation \\
1.3 Lipid Metabolism & Fatty acid biosynthesis \\
1.1 Carbohydrate Metabolism & Pentose phosphate pathway \\
1.7 Glycan Biosynthesis and Metabolism & Glycosylphosphatidylinositol(GPI)-anchor biosynthesis \\
1.6 Metabolism of Other Amino Acids & Selenoamino acid metabolism \\
1.1 Carbohydrate Metabolism & Inositol phosphate metabolism \\
1.1 Carbohydrate Metabolism & Glyoxylate and dicarboxylate metabolism \\
1.7 Glycan Biosynthesis and Metabolism & Glycosaminoglycan degradation \\
\hline 1.7 Glycan Biosynthesis and Metabolism & Glycosphingolipid biosynthesis - ganglio series \\
1.1 Carbohydrate Metabolism & Fructose and mannose metabolism \\
1.3 Lipid Metabolism & Steroid biosynthesis \\
1.3 Lipid Metabolism & Sphingolipid metabolism \\
1.1 Carbohydrate Metabolism & Propanoate metabolism \\
1.1 Carbohydrate Metabolism & Ascorbate and aldarate metabolism \\
1.3 Lipid Metabolism & Biosynthesis of unsaturated fatty acids \\
1.6 Metabolism of Other Amino Acids & Cyanoamino acid metabolism \\
1.8 Metabolism of Cofactors and Vitamins & One carbon pool by folate \\
1.2 Energy Metabolism & Nitrogen metabolism \\
\hline
\end{tabular}

Fig. 6 The top 20 most impacted metabolic Kyoto Encyclopedia of Genes and Genomes Pathways ranked by overall impact values in liver of cows overfed energy prepartum that developed ketosis within 7 days postpartum (KET) or remained healthy (OVE). The impact and flux columns are shown on the right hand side. The impact values are represented by transparent bars ranging from 0 to 50 . The flux values are represented by grey colored bars ranging from -50 to 0 ( - flux) and black colored bars ranging from 0 to +50 (+ flux) based on the direction of the impact. Both groups of cows were fed a diet containing $1.54 \mathrm{Mcal} / \mathrm{kg}$ of dry matter and $15.0 \%$ crude protein from - 21 days prepartum to calving, and a common lactation diet containing $1.75 \mathrm{Mcal} / \mathrm{kg}$ of dry matter and $17.5 \%$ crude protein

lower relative concentrations of glycylvaline, leucylaspartate, and glycylisoleucine agree with the induction of 'Valine, leucine, and isoleucine degradation'. Other induced pathways associated with amino acid metabolism include 'Cysteine and methionine metabolism', 'Arginine and proline metabolism', 'Lysine degradation', 'Tryptophan metabolism', and 'Alanine, aspartate and glutamate metabolism'. It is tempting to speculate, as in metabolomic studies of humans with NAFLD, that activation of amino acid catabolism predisposes cows to ketosis, e.g., by accelerating utilization of essential amino acids close to parturition. This idea is surmised because it is wellestablished that body protein catabolism increases as parturition approaches, hence, partly explaining the lower concentrations of the various metabolites related to these pathways. Alternatively, an increase in catabolism of amino acids such as cysteine and methionine might be related with the need of these compounds for reactions involving synthesis of antioxidants (e.g. glutathione, taurine, hypotaurine), choline, and the methyl donors S-adenosylmethionine $[9,14,41]$. In addition, those amino acids and intermediates such as choline also participate in lipoprotein metabolism, which would encompass cholesterol and choline [32]. The present data underscore the induction of amino acid catabolism as an important feature of clinical ketosis [8], and it highlights a potential opportunity to enhance supplementation of nutrients in the late-prepartum period that might help alleviate those catabolic events.

\section{Glycan biosynthesis and metabolism}

Glycans are carbohydrate molecules that are either linked with lipids to form glycolipids or proteins to form glycoproteins. These carbohydrate molecules are mainly involved in cellular signaling [42]. Cows in KET had an overall inhibition of 'Other glycan degradation', 'Glycosylphosphatidylinositol (GPI)-anchor biosynthesis', 'Glycosaminoglycan degradation', and 'O-Glycan biosynthesis' (Fig. 6), while 'Glycosphingolipid biosynthesis - ganglio series' and 'N-Glycan biosynthesis' were induced. Because of the alterations in cellular function discussed below, we speculate that inhibition of the glycan-related pathways might have contributed to altered cellular signaling, communication, and extracellular matrix (ECM) [43, 44]. In contrast, glycan-related pathway induction might have been associated with a response to help handle misfolded proteins in the endoplasmic reticulum (ER) $[45,46]$. Our previous work with periparturient cows underscored the importance of ER in terms of dealing with stress and inflammation [21]. 


\begin{tabular}{|l|l|l|}
\hline \multicolumn{1}{|c|}{ Sub-Category } & \multicolumn{1}{|c|}{ Non-Metaboloic Pathways } \\
\hline 5.7 Sensory System & Taste transduction & Impact \\
5.6 Nervous System & Long-term potentiation & Renin-angiotensin system \\
5.2 Endocrine System & GnRH signaling pathway \\
5.2 Endocrine System & Ribosome \\
2.2 Translation & mTOR signaling pathway \\
3.2 Signal Transduction & Salivary secretion \\
5.4 Digestive System & Bile secretion \\
5.4 Digestive System & Phototransduction \\
5.7 Sensory System & ErbB signaling pathway \\
3.2 Signal Transduction & Circadian rhythm - mammal \\
\hline 5.9 Environmental Adaptation & Vascular smooth muscle contraction \\
5.3 Circulatory System & Nucleotide excision repair \\
2.4 Replication and Repair & Gastric acid secretion \\
5.4 Digestive System & Insulin signaling pathway \\
5.2 Endocrine System & Gap junction \\
4.4 Cell Communication & Dorso-ventral axis formation \\
5.8 Development & Adherens junction \\
4.4 Cell Communication & Oocyte meiosis \\
4.3 Cell Growth and Death & Glutamatergic synapse \\
5.6 Nervous System & Fnt \\
\hline
\end{tabular}

Fig. 7 The top 20 most impacted non-metabolic Kyoto Encyclopedia of Genes and Genomes Pathways ranked by overall impact values in cows overfed energy prepartum that developed ketosis within 7 days postpartum (KET) or remained healthy (OVE). The impact and flux columns are shown on the right hand side. The impact values are represented by transparent bars ranging from 0 to 50 . The flux values are represented by grey colored bars ranging from -50 to 0 (- flux) and black colored bars ranging from 0 to +50 (+ flux) based on the direction of the impact. Both groups of cows were fed a diet containing $1.54 \mathrm{Mcal} / \mathrm{kg}$ of dry matter and $15.0 \%$ crude protein from - 21 days prepartum to calving, and a common lactation diet containing $1.75 \mathrm{Mcal} / \mathrm{kg}$ of dry matter and $17.5 \%$ crude protein

\section{Metabolism of cofactors and vitamins}

Except for 'Riboflavin metabolism' and 'One carbon pool by folate' (Fig. 6), the remaining pathways associated with cofactors and vitamins (Additional file 1) were induced in KET cows. Riboflavin is part of flavin mononucleotide (FMN) and flavin adenine dinucleotide (FAD) cofactors, which play a critical role in fatty acid oxidation, TCA cycle, the electron transport chain, production of reduced glutathione, and synthesis of 5-methyltetrahydrofolate [47]. The one-carbon metabolism pathway encompasses the methionine cycle, folate cycle, and transsulfuration pathway, all of which interact to generate purines and thymidylate, remethylate homocysteine to methionine, generate SAM, and synthesize antioxidants [48]. Although the benefit of enhancing the supply of methionine in latepregnancy in terms of decreasing risk of metabolic disorders has been confirmed $[9,49,50]$, it is commonly thought that dairy cows do not require dietary water-soluble vitamins due to the contribution from

Table 3 Differentially expressed genes ( $P$-value $<0.01$ and fold-change $\geq$ or $\leq 1.5$ ) associated with glycolysis and gluconeogenesis in liver tissue harvested 10 days prior to parturition from Holstein cows with (KET) or without (OVE) clinical ketosis during the first week postpartum. Both groups of cows were fed a diet containing $1.54 \mathrm{Mcal} / \mathrm{kg}$ of dry matter and $15.0 \%$ crude protein from - 21 days prepartum to calving, and a common lactation diet containing $1.75 \mathrm{Mcal} / \mathrm{kg}$ of dry matter and $17.5 \%$ crude protein

\begin{tabular}{llll}
\hline Symbol & Description & KET vs. OVE & $P$ value \\
\hline FBP2 & Fructose-1,6-bisphosphatase 2 & -8.60 & 0.003 \\
PDK4 & Pyruvate dehydrogenase kinase 4 & -3.35 & 0.028 \\
PDK2 & Pyruvate dehydrogenase kinase, isozyme 2 & -2.27 & 0.018 \\
PFKL & Phosphofructokinase, liver & -1.57 & 0.015 \\
PFKFB2 & 6-phosphofructo-2-kinase/fructose-2,6-biphosphatase 2 & 1.80 & 0.047 \\
PCCA & Propionyl CoA carboxylase, alpha polypeptide & 1.70 & 0.020 \\
PDHB & Pyruvate dehydrogenase (lipoamide) beta (PDHB) & 1.51 & 0.045 \\
PCK1 & Phosphoenolpyruvate carboxykinase 1 (soluble) & 1.51 & 0.035 \\
\hline
\end{tabular}


Table 4 Affected biochemical compounds along with their fold change $(F C)$ values in liver tissue harvested 10 days prior to parturition from Holstein cows with (KET) or without (OVE) clinical ketosis during the first week postpartum. Both groups of cows were fed a diet containing $1.54 \mathrm{Mcal} / \mathrm{kg}$ of dry matter and $15.0 \%$ crude protein from -21 days prepartum to calving, and a common lactation diet containing $1.75 \mathrm{Mcal} / \mathrm{kg}$ of dry matter and $17.5 \%$ crude protein.

\begin{tabular}{|c|c|c|c|}
\hline \multirow[t]{2}{*}{ Compound } & \multirow[t]{2}{*}{ Pathway or category } & \multicolumn{2}{|c|}{ KET vs. OVE } \\
\hline & & FC & $P$-value \\
\hline Glycylvaline & Dipeptide & -1.41 & 0.01 \\
\hline Leucylaspartate & Dipeptide & -1.46 & 0.01 \\
\hline Tyrosylglycine & Dipeptide & -1.30 & 0.03 \\
\hline Glycylisoleucine & Dipeptide & -1.49 & 0.03 \\
\hline Xylitol & Pentose metabolism & -1.34 & 0.04 \\
\hline 1-Palmitoylglycerophosphoglycerol & Lysolipid & -1.37 & 0.06 \\
\hline Glycochenodeoxycholate & Primary bile acid metabolism & 2.32 & 0.06 \\
\hline Glucose-6-phosphate & Glycolysis, gluconeogenesis, and pyruvate metabolism & -1.24 & 0.07 \\
\hline 1-Methylimidazoleacetate & Histidine metabolism & 1.62 & 0.07 \\
\hline D-Erythro-C16-ceramide ${ }^{a}$ & Sphingolipid metabolism & -1.24 & 0.07 \\
\hline 1-Nonadecanoylglycerophosphocholine & Lysolipid & -3.79 & 0.08 \\
\hline 3-Dehydrocarnitine & Carnitine metabolism & -1.15 & 0.08 \\
\hline Ribulose & Pentose metabolism & -1.29 & 0.09 \\
\hline Butyrylglycine & Fatty acid metabolism (also BCAA metabolism) & 1.34 & 0.09 \\
\hline Tetradecanedioate & Fatty acid, dicarboxylate & -1.40 & 0.09 \\
\hline Kynurenine & Tryptophan metabolism & -2.12 & 0.10 \\
\hline 1-Oleoylglycerophosphoethanolamine & Lysolipid & -1.54 & 0.10 \\
\hline Cytidine 5'-diphosphocholine & Phospholipid metabolism & 1.17 & 0.10 \\
\hline
\end{tabular}

${ }^{a}$ Also known as N-palmitoyl-D-erythro-sphingosine

ruminal microbes. Clearly, these data highlight a number of interrelated pathways whose activity is altered in late-pregnancy in cows that develop ketosis. Further studies should measure activities of some the key enzymes in these pathways to better understand the relationship with nutrition and management of the cow prior to parturition. From the present data, it is unclear if activity and/or flux through the pathways also are compromised in cows that become susceptible to ketosis.

\section{Non-metabolic pathways Translation}

'Ribosome' was one of only two non-metabolic pathways that was activated among the top 20 most-impacted in KET (Fig. 7). Along with other pathways such as 'Ribosome biogenesis in eukaryotes', 'RNA transport', and 'mRNA surveillance pathway' (Additional file 1), 'Ribosome' is involved in cellular protein synthesis and turnover. Several pathways related to folding, sorting, and degradation also were induced, including 'Protein processing in endoplasmic reticulum', 'RNA degradation', 'Protein export', 'Ubiquitin-mediated proteolysis', and 'Proteasome'. Together, these results indicate that genes involved in the various aspects of cellular protein homeostasis within the liver were altered prior to parturition in cows prone to develop ketosis.

The importance of genes associated with protein homeostasis in the context of the normal adaptations of the liver to the onset of lactation have been discussed previously [51,52]. More recent data have confirmed the biological importance of those networks in the periparturient period. For instance, ER stress induced an unfolded protein response (UPR) that was associated with changes in mRNA expression during the transition period [53, 54]. The differential expression of genes associated with the ER stress and UPR in prepartum cows that are susceptible to ketosis may reflect an inflammatory response. However, the fact that systemic biomarkers of inflammation and oxidant status did not differ between KET and OVE cows suggests the existence of "localized" inflammatory mechanisms. For instance, the expression of chemokine ( $\mathrm{C}-\mathrm{C}$ motif) ligand 2 (CCL2) had the highest degree of upregulation in KET cows (Table 1). We have detected alterations in mRNA abundance of CCL2 in adipose tissue and neutrophils during the periparturient period [55-57]. Furthermore, we were the first to profile immune-responsive genes not only in periparturient liver [51], but also in cows with clinical ketosis [22]. Thus, a linkage between early 
inflammatory activation within the liver and aspects of cellular protein homeostasis might predispose cows to ketosis, especially when overfed energy prepartum.

\section{DNA replication}

The pathways related to DNA replication such as 'Nucleotide excision repair', 'Base excision repair', and 'DNA replication' were induced in cows with KET (Fig. 7, Additional file 1). The induction of these pathways seems to suggest an increase in liver regeneration and/or cell proliferation. Similar mechanisms of cellular proliferation were altered in cows with ketosis in the early postpartum period $[22,58]$. As an example, the transcription regulator MECOM (MDS1 and EVI1 complex locus) (Fig. 3a) is involved in regulation of cellular proliferation (SKIL) [59] and also transcription of metabolism and bile acid synthesis-related genes (ACACA, ACAA2) [60]. However, whether such effect would be detrimental to hepatic health and render cows more susceptible to ketosis would require more detailed studies.

\section{Cellular functions}

During metabolic disorders, several cellular functions are affected [22]. In the KET vs. OVE group, the inhibited pathways included the 'mTOR signaling pathway', 'ErbB signaling pathway', 'VEGF signaling pathway', 'Phosphatidylinositol signaling system', 'MAPK signaling pathway', 'Calcium signaling pathway', 'Hedgehog signaling pathway', 'Notch signaling pathway', 'Wnt signaling pathway', and 'Jak-STAT signaling pathway'. In contrast, the 'TGF-beta signaling pathway' was the only induced pathway in cows with KET (Additional file 1).

The inhibition of these various signaling pathways may indicate a lower degree of cell-to-cell communication, and a lack of proper signaling mechanisms that could predispose cows to ketosis. The inhibition of these signaling pathways likely would have led to compromising several important biologic functions including a decrease in cell metabolism (e.g., mTOR, Phosphatidylinositol, Calcium, Notch) [61-63], growth, proliferation and survival (e.g., mTOR, ErbB, MAP Kinase, Hedgehog, Wnt) $[64,65]$, a reduction in differentiation, apoptosis, and cell motility (e.g., ErbB, MAP Kinase, Phosphatidylinositol, Notch, Wnt) [66, 67], a decrease in vascular development (VEGF) [68] and immune response (Jak-STAT, MAP Kinase) [69, 70]. Unlike the multitude of inhibited pathways, the induction of TGF-beta signaling along with downstream target genes such as SMAD1, TGIF1, and BAMBI (Additional file 1) might have been an indication of enhanced cell proliferation and apoptosis regulation [71], i.e., a counter-regulatory response to maintain normal cellular function.

Ingenuity pathway analysis of functional connections between glycochenodeoxycholate, D-erythro-C16 ceramide and glucose-6-phosphate and cellular function and maintenance categories highlighted important associations (Fig. 4b). For instance, increases or accumulation of glycochenodeoxycholate triggers depolarization of mitochondria leading to hepatocyte apoptosis, and alterations in reactive oxygen species generation [72, 73]. The lower concentration of D-erythro-C16 ceramide (Fig. 4b, and Fig. 5) might suggest a decrease in functioning of adherens and tight junctions, both of which play an important role in epithelial cell to cell adhesion [74]. In that context, it is noteworthy to note that ceramides also are important cell signaling lipid molecules able to participate in the control of apoptosis, growth, differentiation and proliferation $[75,76]$.

\section{Immune system}

The role of the liver as a responder to the stresses characteristic of the periparturient period is well-known [77]. Hepatic transcriptome analyses have revealed not only metabolic networks, but also immune networks that likely contribute to the immune-responsiveness of the organ [51, 78]. Plasma analyses of inflammation biomarkers such as albumin, ceruloplasmin, serum amyloid A (SAA), haptoglobin and interleukin 6 (IL-6) during the transition into lactation not only help understand the normal course of inflammatory process in dairy cows, but also the potential benefits that nutritional management can have on those processes [79]. The liver synthesizes a number of acute-phase proteins [77], hence, transcriptome analyses of this organ can provide additional information about a localized inflammatory response, especially around calving. More importantly, such data can be used to gauge potential linkages with other important biological adaptations of the liver that occur at the transcriptome level, e.g. alterations in lipid metabolism and mitochondrial function [80, 81].

Among the immune-related pathways, bioinformatics analyses revealed that 'Antigen processing and presentation' and 'Complement and coagulation cascades' (Additional file 1) were the most induced in KET compared with OVE cows. In addition, among the up-regulated transcription factors, our data suggest that HIF1A, HMGB1, and NFE2L2 (Fig. 5) are biologically linked with downstream immune-related genes such as INFG and TNF. Among these, HIF1A is mainly involved in regulation of cell metabolism, stress, and innate immune response [82]. The protein encoded by $H M G B 1$ acts as a cytokine to respond against cellular injury, infection, and inflammation [83]. The transcription factor NFE2L2 is an important regulator of oxidative stress and helps control pro-inflammatory responses in non-ruminants [84] and dairy cows [85, 86]. Although the systemic concentrations of immune-related biomarkers did not differ between KET and OVE (Additional file 3), these molecular data suggest that ketosis postpartum might be 
associated with a localized inflammatory response. As such, if this inflammatory response is not properly controlled it might be a causative factor associated with the various cellular signaling events that were inhibited in cows with KET.

\section{Conclusions}

Despite the lack of difference in dry matter intake prior to parturition, both transcriptome and metabolome analyses of liver tissue revealed altered profiles between KET and OVE cows in late-pregnancy, some of which might contribute to onset of ketosis soon after parturition. The combined data analyses revealed more extensive alterations of the liver transcriptome than metabolome in cows overfed energy during the prepartal period and developing ketosis postpartum. It is noteworthy that, in the present study, clinical ketosis postpartum in response to energy overfeeding prepartum was not only related to carbohydrate and lipid metabolism, but also amino acid and vitamin metabolism. Besides metabolism, impaired cellular immune function and inhibition of important cellular signaling pathways also might play a crucial role in leading to ketosis. The causative link between these tissue-level adaptations and onset of clinical ketosis needs to be studied further.

\section{Supplementary information}

Supplementary information accompanies this paper at https://doi.org/10. 1186/s40104-019-0404-z

Additional file 1. Differentially expressed genes (DEG), overall summary of the bioinformatics analysis using the Dynamic Impact Approach (DIA), and individual categories and subcategories affected by the DEG in cows developing ketosis postpartum.

Additional file 2. Biochemical compounds identified by the metabolomics analysis of liver tissue.

Additional file 3. Profiles of biomarkers analyzed in plasma, and statistical output.

\section{Abbreviations}

BHB: Hydroxybutyrate; CP: Crude protein; DEG: Differentially expressed genes; DIA: Dynamic impact approach; DM: Dry matter; IACUC: Institutional Animal Care and Use Committee; IPA: Ingenuity pathway analysis; KEGG: Kyoto Encyclopedia of Genes and Genomes; KET: Ketosis; NEB: Negative energy balance; OVE: Control, healthy cows

\section{Acknowledgements}

Yusheng Liang was a recipient of PhD fellowship from China Scholarship Council (CSC) (Beijing) to perform his PhD studies at the University of Illinois (Urbana).

\section{Authors'contribution}

$J \mathrm{~L}$ conceived and designed the experiments. JSO managed cows and collected performance data. JSO, VL, YL, ET, and CX harvested samples, performed lab analyses, or helped interpret the data. KS performed transcriptome analyses and statistical analyses of all data. $\mathrm{KS}, \mathrm{VL}, \mathrm{YL}$, JSO, and $J \mathrm{~J}$ wrote the manuscript. All authors read and approved the final version of the manuscript.

\section{Authors' information}

K. Shahzad, Assistant Professor, COMSATS Institute of Information Technology, ChakShahzad, Islamabad, 44000, Pakistan. V. Lopreiato, Post-doc fellow, Istituto di Zootecnica, Facoltà di Scienze Agrarie, Alimentari e Ambientali, Università Cattolica del Sacro Cuore, Piacenza, 29122, Italy. Y. Liang, PhD student, Department of Animal Sciences and Division of Nutritional Sciences, University of Illinois, Urbana, Illinois 61801, USA. E. Trevisi, Associate Professor, Istituto di Zootecnica, Facoltà di Scienze Agrarie, Alimentari e Ambientali, Università Cattolica del Sacro Cuore, Piacenza, 29122, Italy. J. S. Osorio, Assistant Professor, Department of Dairy Science, South Dakota State University, Brookings, SD, 57006, USA. C. Xu, Professor, College of Animal Science and Veterinary Medicine, Heilongjiang Bayi Agricultural University, Xinyang Rd. 5, 163319 Daqing. J. J. Loor, Professor, Department of Animal Sciences and Division of Nutritional Sciences, University of Illinois, Urbana, Illinois 61801, USA.

\section{Funding}

Not applicable.

\section{Availability of data and materials}

The datasets analyzed during the current study are available from the corresponding author on reasonable request.

\section{Ethics approval and consent to participate}

The research protocol was approved by the Institutional Animal Care and Use Committee of the University of Illinois (protocol no. 09214).

\section{Consent for publication}

Not applicable.

\section{Competing interests}

The authors declare that they have no competing interests.

\section{Author details}

${ }^{1}$ COMSATS Institute of Information Technology, ChakShahzad, Islamabad 44000, Pakistan. ${ }^{2}$ Department of Animal Sciences and Division of Nutritional Sciences, University of Illinois, Urbana, IL 61801, USA. ${ }^{3}$ Istituto di Zootecnica, Facoltà di Scienze Agrarie, Alimentari e Ambientali, Università Cattolica del Sacro Cuore, 29122 Piacenza, Italy. ${ }^{4}$ Department of Dairy Science, South Dakota State University, Brookings, SD 57006, USA. ${ }^{5}$ College of Animal Science and Veterinary Medicine, Heilongjiang Bayi Agricultural University, Xinyang Rd. 5, Daqing 163319, China.

Received: 4 July 2019 Accepted: 11 November 2019

Published online: 18 December 2019

\section{References}

1. Baird GD. Primary ketosis in the high-producing dairy cow: clinical and subclinical disorders, treatment, prevention, and outlook. J Dairy Sci. 1982;65:1-10.

2. Berge AC, Vertenten G. A field study to determine the prevalence, dairy herd management systems, and fresh cow clinical conditions associated with ketosis in western European dairy herds. J Dairy Sci. 2014;97:2145-54.

3. Drackley JK. ADSA Foundation scholar award. Biology of dairy cows during the transition period: the final frontier? J Dairy Sci. 1999:82:2259-73.

4. Morrow DA, Hillman D, Dade AW, Kitchen Y. Clinical investigation of a dairy herd with the fat cow syndrome. J Am Vet Med Assoc. 1979;174:161-7.

5. Grummer RR, Mashek DG, Hayirli A. Dry matter intake and energy balance in the transition period. Vet Clin North Am Food Anim Pract. 2004;20:447-70.

6. Ceciliani F, Vecchio D, De Carlo E, Martucciello A, Lecchi C. A systems biology approach to dairy cattle subfertility and infertility. In: Periparturient diseases of dairy cows. edn ed. Switzerland: Springer International Publishing; 2017. p. 93-119.

7. Li Y, Xu C, Xia C, Zhang H, Sun L, Gao Y. Plasma metabolic profiling of dairy cows affected with clinical ketosis using LC/MS technology. Vet Q. 2014;34:152-8.

8. Z Zhang HY, Wu L, Xu C, Xia C, Sun LW, Shu S. Plasma metabolomic profiling of dairy cows affected with ketosis using gas chromatography/mass spectrometry. BMC Vet Res. 2013;9:136.

9. Osorio J, Ji P, Drackley J, Luchini D, Loor JJ. Supplemental Smartamine M or MetaSmart during the transition period benefits postpartal cow performance and blood neutrophil function. J Dairy Sci. 2013;96:6248-63. 
10. Dann HM, Litherland NB, Underwood JP, Bionaz M, D'Angelo A, McFadden JW, et al. Diets during far-off and close-up dry periods affect periparturient metabolism and lactation in multiparous cows. J Dairy Sci. 2006;89:3563-77.

11. Osorio J, Ji P, Drackley J, Luchini D, Loor JJ. Smartamine M and MetaSmart supplementation during the peripartal period alter hepatic expression of gene networks in 1-carbon metabolism, inflammation, oxidative stress, and the growth hormone-insulin-like growth factor 1 axis pathways. J Dairy Sci. 2014;97:7451-64.

12. Shahzad K, Akbar H, Vailati-Riboni M, Basirico L, Morera P, Rodriguez-Zas SL, et al. The effect of calving in the summer on the hepatic transcriptome of Holstein cows during the peripartal period. J Dairy Sci. 2015;98:5401-13.

13. Agrawal A, Khan M, Graugnard D, Vailati-Riboni M, Rodriguez-Zas SL, Osorio J, et al. Prepartal energy intake alters blood polymorphonuclear leukocyte transcriptome during the peripartal period in Holstein cows. Bioinform Biol Insights. 2017;11:1177932217704667.

14. Zhou Z, Bulgari O, Vailati-Riboni M, Trevisi E, Ballou M, Cardoso F, et al. Rumen-protected methionine compared with rumen-protected choline improves immunometabolic status in dairy cows during the peripartal period. J Dairy Sci. 2016;99:8956-69.

15. Batistel F, Arroyo JM, Bellingeri A, Wang L, Saremi B, Parys C, et al. Ethylcellulose rumen-protected methionine enhances performance during the periparturient period and early lactation in Holstein dairy cows. J Dairy Sci. 2017; 100:7455-67.

16. Batistel F, Arroyo J, Garces C, Trevisi E, Parys C, Ballou M, et al. Ethyl-cellulose rumen-protected methionine alleviates inflammation and oxidative stress and improves neutrophil function during the periparturient period and early lactation in Holstein dairy cows. J Dairy Sci. 2018;101:480-90.

17. Osorio J, Trevisi E, Li C, Drackley JK, Socha M, Loor JJ. Supplementing Zn, $\mathrm{Mn}$, and cu from amino acid complexes and co from cobalt glucoheptonate during the peripartal period benefits postpartal cow performance and blood neutrophil function. J Dairy Sci. 2016;99:1868-83.

18. Bionaz M, Periasamy K, Rodriguez-Zas SL, Hurley WL, Loor JJ. A novel dynamic impact approach (DIA) for functional analysis of time-course omics studies: validation using the bovine mammary transcriptome. PLoS One. 2012;7:e32455

19. Zandkarimi F, Vanegas J, Fern X, Maier C, Bobe G. Metabotypes with elevated protein and lipid catabolism and inflammation precede clinical mastitis in prepartal transition dairy cows. J Dairy Sci. 2018;101:5531-48.

20. Gitto S, Schepis F, Andreone P, Villa E. Study of the serum metabolomic profile in nonalcoholic fatty liver disease: research and clinical perspectives. Metabolites. 2018:8:17.

21. Kalhan SC, Guo L, Edmison J, Dasarathy S, McCullough AJ, Hanson RW, et al. Plasma metabolomic profile in nonalcoholic fatty liver disease. Metabolism. 2011:60:404-13.

22. Loor JJ, Everts RE, Bionaz M, Dann HM, Morin DE, Oliveira R, et al. Nutritioninduced ketosis alters metabolic and signaling gene networks in liver of periparturient dairy cows. Physiol Genomics. 2007:32:105-16.

23. Li YC, Su ZR, Lin SH, Li CW, Zhao Y, Gao X, et al. Characterisation of the metabolism of pogostone in vitro and in vivo using liquid chromatography with mass spectrometry. Phytochem Anal. 2014;25:97-105.

24. Dervishi E, Zhang G, Dunn SM, Mandal R, Wishart DS, Ametaj BN. GC-MS metabolomics identifies metabolite alterations that precede subclinical mastitis in the blood of transition dairy cows. J Proteome Res. 2017:16:433-46.

25. Humer E, Khol-Parisini A, Metzler-Zebeli BU, Gruber L, Zebeli Q. Alterations of the lipid metabolome in dairy cows experiencing excessive lipolysis early postpartum. PLoS One. 2016;11:e0158633.

26. Ferreira AM, Bislev SL, Bendixen E, Almeida AM. The mammary gland in domestic ruminants: a systems biology perspective. J Proteome. 2013; 94:110-23.

27. Landau BR, Bartsch GE, Williams HR. Estimation of the glucuronic acid pathway contribution to glucose metabolism in adipose tissue and the effect of growth hormone. J Biol Chem. 1966;241:750-60.

28. Dupriez VJ, Rousseau GG. Glucose response elements in a gene that codes for 6-phosphofructo-2-kinase/fructose-2,6-bisphosphatase. DNA Cell Biol. 1997; 16:1075-85.

29. Keller U, Froesch E. Metabolism and oxidation of U-14 C-glucose, xylitol, fructose and sorbitol in the fasted and in the streptozotocin-diabetic rat. Diabetologia. 1971;7:349-56.

30. Hamada T, Ishii T, Taguchi S. Blood changes of spontaneously ketotic cows before and four hours after administration of glucose, xylitol, 1, 2propanediol, or magnesium propionate. J Dairy Sci. 1982;65:1509-13.
31. Hofmann AF. The continuing importance of bile acids in liver and intestinal disease. Arch Intern Med. 1999;159:2647-58.

32. Piantoni $P$, Wang $P$, Drackley JK, Hurley WL, Loor JJ. Expression of metabolic, tissue remodeling, oxidative stress, and inflammatory pathways in mammary tissue during involution in lactating dairy cows. Bioinform Biol Insights. 2010;4:85-97.

33. Desvergne $B$, Michalik L, Wahli W. Transcriptional regulation of metabolism. Physiol Rev. 2006;86:465-514.

34. Daemen $\mathrm{S}$, Kutmon M, Evelo CT. A pathway approach to investigate the function and regulation of SREBPs. Genes Nutr. 2013:8:289-300.

35. Min HK, Kapoor A, Fuchs M, Mirshahi F, Zhou H, Maher J, et al. Increased hepatic synthesis and dysregulation of cholesterol metabolism is associated with the severity of nonalcoholic fatty liver disease. Cell Metab. 2012;15:665-74.

36. Caballero F, Fernandez A, De Lacy AM, Fernandez-Checa JC, Caballeria J, Garcia-Ruiz C. Enhanced free cholesterol, SREBP-2 and StAR expression in human NASH. J Hepatol. 2009;50:789-96.

37. Tetens J, Heuer C, Heyer I, Klein MS, Gronwald W, Junge W, et al. Polymorphisms within the APOBR gene are highly associated with milk levels of prognostic ketosis biomarkers in dairy cows. Physiol Genomics. 2015:47:129-37.

38. Duffield T. Subclinical ketosis in lactating dairy cattle. Vet Clin North Am Food Anim Pract. 2000;16:231-53.

39. Gillund P, Reksen O, Gröhn Y, Karlberg K. Body condition related to ketosis and reproductive performance in Norwegian dairy cows. J Dairy Sci. 2001; 84:1390-6.

40. Rasmussent L, Nielsen BL, Pryce J, Mottram T, Veerkamp R. Risk factors associated with the incidence of ketosis in dairy cows. Anim Sci. 1999;68: 379-86.

41. Zhou Z, Garrow TA, Dong X, Luchini DN, Loor JJ. Hepatic activity and transcription of betaine-homocysteine methyltransferase, methionine synthase, and cystathionine synthase in periparturient dairy cows are altered to different extents by supply of methionine and choline-3. J Nutr. 2016:147:11-9.

42. Shahzad K, Bionaz M, Trevisi E, Bertoni G, Rodriguez-Zas SL, Loor JJ. Integrative analyses of hepatic differentially expressed genes and blood biomarkers during the peripartal period between dairy cows overfed or restricted-fed energy prepartum. PLoS One. 2014;9:e99757.

43. Ernst $\mathrm{S}$, Langer $\mathrm{R}$, Cooney $\mathrm{CL}$, Sasisekharan R. Enzymatic degradation of glycosaminoglycans. Crit Rev Biochem Mol Biol. 1995;30:387-444.

44. Wopereis S, Lefeber DJ, Morava E, Wevers RA. Mechanisms in protein Oglycan biosynthesis and clinical and molecular aspects of protein O-glycan biosynthesis defects: a review. Clin Biochem. 2006;52:574-600.

45. Lingwood CA. Glycosphingolipid functions. Cold Spring Harb Perspect Biol. 2011;3.

46. Ruddock LW, Molinari M. N-glycan processing in ER quality control. J Cell Sci. 2006:119:4373-80.

47. Powers HJ. Riboflavin (vitamin B-2) and health. Am J Clin Nutr. 2003;77:1352-60.

48. Stover PJ. One-carbon metabolism-genome interactions in folate-associated pathologies. J Nutr. 2009;139:2402-5.

49. Sun F, Cao Y, Cai C, Li S, Yu C, Yao J. Regulation of nutritional metabolism in transition dairy cows: energy homeostasis and health in response to postruminal choline and methionine. PLoS One. 2016;11:e0160659.

50. Zhou Z, Vailati-Riboni M, Luchini DN, Loor JJ. Methionine and choline supply during the periparturient period alter plasma amino acid and onecarbon metabolism profiles to various extents: potential role in hepatic metabolism and antioxidant status. Nutrients. 2016:9:10.

51. Loor JJ. Genomics of metabolic adaptations in the peripartal cow. Animal. 2010:4:1110-39.

52. Bionaz M, Loor JJ. Ruminant metabolic systems biology: reconstruction and integration of transcriptome dynamics underlying functional responses of tissues to nutrition and physiological state. Gene Regul Syst Bio. 2012;6:S9852.

53. Gessner DK, Schlegel G, Ringseis R, Schwarz FJ, Eder K. Up-regulation of endoplasmic reticulum stress induced genes of the unfolded protein response in the liver of periparturient dairy cows. BMC Vet Res. 2014;10:46

54. Winkler A, Gessner DK, Koch C, Romberg FJ, Dusel G, Herzog E, et al. Effects of a plant product consisting of green tea and curcuma extract on milk production and the expression of hepatic genes involved in endoplasmic stress response and inflammation in dairy cows. Arch Anim Nutr. 2015;69:425-41. 
55. Zhou Z, Bu D, Riboni MV, Khan M, Graugnard D, Luo J, et al. Preparta dietary energy level affects peripartal bovine blood neutrophil metabolic, antioxidant, and inflammatory gene expression. J Dairy Sci. 2015:98:5492-505.

56. Vailati-Riboni M, Kanwal M, Bulgari O, Meier S, Priest N, Burke C, et al. Body condition score and plane of nutrition prepartum affect adipose tissue transcriptome regulators of metabolism and inflammation in grazing dairy cows during the transition period. J Dairy Sci. 2016;99:758-70.

57. Crookenden M, Heiser A, Murray A, Dukkipati V, Kay J, Loor JJ, et al. Parturition in dairy cows temporarily alters the expression of genes in circulating neutrophils. J Dairy Sci. 2016;99:6470-83.

58. McCarthy SD, Waters SM, Kenny DA, Diskin MG, Fitzpatrick R, Patton J, et al. Negative energy balance and hepatic gene expression patterns in highyielding dairy cows during the early postpartum period: a global approach. Physiol Genomics. 2010;42A:188-99.

59. Kim I, Lee SH, Jeong J, Park JH, Yoo MA, Kim CM. Functional profiling of human MeCP2 by automated data comparison analysis and computerized expression pathway modeling. Healthc Inform Res. 2016;22:120-8.

60. Nakamura MT, Yudell BE, Loor JJ. Regulation of energy metabolism by longchain fatty acids. Prog Lipid Res. 2014;53:124-44.

61. Laplante M, Sabatini DM. mTOR signaling at a glance. J Cell Sci. 2009;122: 3589-94.

62. Kuhla B, Albrecht D, Kuhla S, Metges CC. Proteome analysis of fatty liver in feed-deprived dairy cows reveals interaction of fuel sensing, calcium, fatty acid, and glycogen metabolism. Physiol Genomics. 2009; 37:88-98.

63. Arai Y, Shibata T, Matsuoka S, Sato MJ, Yanagida T, Ueda M. Selforganization of the phosphatidylinositol lipids signaling system for random cell migration. Proc Natl Acad Sci U S A. 2010;107:12399-404.

64. Hynes NE, MacDonald G. ErbB receptors and signaling pathways in cancer. Curr Opin Cell Biol. 2009;21:177-84.

65. Varjosalo M, Taipale J. Hedgehog: functions and mechanisms. Genes Dev. 2008;22:2454-72.

66. Guruharsha KG, Kankel MW, Artavanis-Tsakonas S. The notch signalling system: recent insights into the complexity of a conserved pathway. Nat Rev Genet. 2012;13:654-66

67. MacDonald BT, Tamai K, He X. Wnt/beta-catenin signaling: components, mechanisms, and diseases. Dev Cell. 2009;17:9-26.

68. Zhang C, Wang G, Wang J, Ji Z, Dong F, Chao T. Analysis of differential gene expression and novel transcript units of ovine muscle transcriptomes. PLoS One. 2014;9:e89817.

69. Shuai K, Liu B. Regulation of JAK-STAT signalling in the immune system. Nat Rev Immunol. 2003;3:900-11.

70. Arthur JS, Ley SC. Mitogen-activated protein kinases in innate immunity. Nat Rev Immunol. 2013;13:679-92.

71. Heldin CH, Miyazono K, ten Dijke P. TGF-beta signalling from cell membrane to nucleus through SMAD proteins. Nature. 1997;390:465-71.

72. Lemasters JJ, Nieminen AL, Qian T, Trost LC, Elmore SP, Nishimura Y, et al. The mitochondrial permeability transition in cell death: a common mechanism in necrosis, apoptosis and autophagy. Biochim Biophys Acta. 1998;1366:177-96.

73. Higuchi H, Bronk SF, Takikawa Y, Werneburg N, Takimoto R, El-Deiry W, et al. The bile acid glycochenodeoxycholate induces trail-receptor 2/DR5 expression and apoptosis. J Biol Chem. 2001;276:38610-8.

74. Yap AS, Brieher WM, Gumbiner BM. Molecular and functional analysis of cadherin-based adherens junctions. Annu Rev Cell Dev Biol. 1997;13:119-46.

75. Kjellberg MA, Lonnfors M, Slotte JP, Mattjus P. Metabolic conversion of ceramides in HeLa cells - a cholesteryl phosphocholine delivery approach. PLoS One. 2015:10:e0143385.

76. Wang G, Krishnamurthy K, Umapathy NS, Verin AD, Bieberich E. The carboxyl-terminal domain of atypical protein kinase Czeta binds to ceramide and regulates junction formation in epithelial cells. J Biol Chem. 2009;284:14469-75.

77. Loor JJ, Bertoni G, Hosseini A, Roche J, Trevisi E. Functional welfare-using biochemical and molecular technologies to understand better the welfare state of peripartal dairy cattle. Anim Prod Sci. 2013;53:931-53.

78. Li X, Huang W, Gu J, Du X, Lei L, Yuan X, et al. SREBP-1c overactivates ROS mediated hepatic NF-KB inflammatory pathway in dairy cows with fatty liver. Cell Signal. 2015;27:2099-109.

79. Osorio JS, Trevisi E, Ji P, Drackley JK, Luchini D, Bertoni G, et al. Biomarkers of inflammation, metabolism, and oxidative stress in blood, liver, and milk reveal a better immunometabolic status in peripartal cows supplemented with Smartamine M or MetaSmart. J Dairy Sci. 2014;97:7437-50.

80. Zhu Y, Liu G, Du X, Shi Z, Jin M, Sha X, et al. Expression patterns of hepatic genes involved in lipid metabolism in cows with subclinical or clinical ketosis. J Dairy Sci. 2019;102:1725-35.

81. Du X, Shen T, Wang H, Qin X, Xing D, Ye Q, et al. Adaptations of hepatic lipid metabolism and mitochondria in dairy cows with mild fatty liver. J Dairy Sci. 2018;101:9544-58.

82. Nizet $\mathrm{V}$, Johnson RS. Interdependence of hypoxic and innate immune responses. Nat Rev Immunol. 2009;9:609-17.

83. Lotze MT, Tracey KJ. High-mobility group box 1 protein (HMGB1): nuclear weapon in the immune arsenal. Nat Rev Immunol. 2005;5:331-42.

84. Figarska SM, Vonk JM, Boezen HM. NFE2L2 polymorphisms, mortality, and metabolism in the general population. Physiol Genomics. 2014;46:411-7.

85. Ma Y, Wu Z, Gao M, Loor JJ. Nuclear factor erythroid 2-related factor 2antioxidant activation through the action of ataxia telangiectasia-mutated serine/threonine kinase is essential to counteract oxidative stress in bovine mammary epithelial cells. J Dairy Sci. 2018;101:5317-28.

86. Ma Y, Wu Z, Gao M, Loor JJ. Nuclear factor erythroid 2-related factor 2 antioxidant response element pathways protect bovine mammary epithelial cells against $\mathrm{H}_{2} \mathrm{O}_{2}$-induced oxidative damage in vitro. J Dairy Sci. 2018;101: 5329-44.

\section{Ready to submit your research? Choose BMC and benefit from:}

- fast, convenient online submission

- thorough peer review by experienced researchers in your field

- rapid publication on acceptance

- support for research data, including large and complex data types

- gold Open Access which fosters wider collaboration and increased citations

- maximum visibility for your research: over $100 \mathrm{M}$ website views per year

At BMC, research is always in progress.

Learn more biomedcentral.com/submissions 